\title{
Effects of high intraoperative inspired oxygen on postoperative nausea and vomiting in gynecologic laparoscopic surgery
}

Tatjana Šimurina, MD, MSc

General Hospital, Zadar, Croatia

Boris Mraović, MD

Thomas Jefferson University

Simon Mikulandra, MD, MSc

Clinical Hospital Center, Zagreb, Croatia

Zdenko Sonicki, MD, PhD

University of Zagreb, Zagreb, Croatia

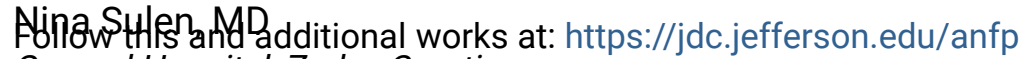
General Hospital, Zadar, Croatia

Part of the Anesthesiology Commons, and the Cardiology Commons

\section{Let us know how access to this document benefits you See next page for additional authors}

\section{Recommended Citation}

Šimurina, MD, MSc, Tatjana; Mraović, MD, Boris; Mikulandra, MD, MSc, Simon; Sonicki, MD, PhD, Zdenko; Sulen, MD, Nina; Dukić, MD, Branko; and Gan, M.D, Tong J., "Effects of high intraoperative inspired oxygen on postoperative nausea and vomiting in gynecologic laparoscopic surgery" (2010). Department of Anesthesiology Faculty Papers. Paper 13. https://jdc.jefferson.edu/anfp/13

This Article is brought to you for free and open access by the Jefferson Digital Commons. The Jefferson Digital Commons is a service of Thomas Jefferson University's Center for Teaching and Learning (CTL). The Commons is a showcase for Jefferson books and journals, peer-reviewed scholarly publications, unique historical collections from the University archives, and teaching tools. The Jefferson Digital Commons allows researchers and interested readers anywhere in the world to learn about and keep up to date with Jefferson scholarship. This article has been accepted for inclusion in Department of Anesthesiology Faculty Papers by an authorized administrator of the Jefferson Digital Commons. For more information, please contact: JeffersonDigitalCommons@jefferson.edu. 


\section{Authors}

Tatjana Šimurina, MD, MSc; Boris Mraović, MD; Simon Mikulandra, MD, MSc; Zdenko Sonicki, MD, PhD; Nina Sulen, MD; Branko Dukić, MD; and Tong J. Gan, M.D 


\title{
As submitted to:
}

\author{
Journal of Clinical Anesthesia
}

And later published as:

\section{Effects of high intraoperative inspired oxygen on postoperative}

\author{
nausea and vomiting in gynecologic laparoscopic surgery \\ Volume 22, Issue 7, 2010, Pages 492-498 \\ DOI: 10.1016/j.jclinane.2009.10.013
}

Short title: Oxygen in prevention of PONV

Tatjana Šimurina, MD, MSc (Anesthesiologist) ${ }^{1 *}$, Boris Mraović, MD ( Anesthesiologist, Associate Professor of Anesthesiology)2, Simon Mikulandra, MD, MSc (Anesthesiologist) ${ }^{3}$, Zdenko Sonicki, MD, PhD (Associate Professor) ${ }^{4}$, Nina Sulen, MD (Anesthesiologist) ${ }^{1}$, Branko Dukić, MD (Gynecologist) ${ }^{5}$, Tong J. Gan, M.D (Anesthesiologist, Professor of Anesthesiology ${ }^{6}$

${ }^{1}$ Department of Anesthesiology and Intensive Care Unit, General Hospital, Zadar, Croatia ${ }^{2}$ Department of Anesthesiology, Thomas Jefferson University, Philadelphia, PA, USA ${ }^{3}$ Department of Anesthesiology and Critical Care, Clinical Hospital Center, Zagreb, Croatia ${ }^{4}$ Department of Medical Statistics, Epidemiology and Medical Informatics, School of Public Health «Andrija Štampar», University of Zagreb, Zagreb, Croatia ${ }^{5}$ Department of Gynecology and Obstetrics, General Hospital, Zadar, Croatia ${ }^{6}$ Department of Anesthesiology, Duke University Medical Center, Durham, NC, USA This work was carried out at the Department of Anesthesiology and Intensive Care Unit, General Hospital, Zadar, Croatia. Presented at ASA meeting, Orlando, October 2008 and CAS meeting, Vancouver, June 2009. Partly supported by the Croatian Ministry of Science, 
Education and Sport; research project "Predictive Models in Health Care" No. 108-09825600257.

*Corresponding author: General Hospital Zadar, Bože Peričića 5, 23000 Zadar, Croatia, Phone: +385 23 315677, Fax: +385 23 311969, Email: tatjana_simurina@yahoo.com

Word Count: 2406

Conflict of Interest: none.

Keywords: Postoperative nausea and vomiting, Gynecologic surgery, Laparoscopy, Oxygen/Administration and dosage 


\section{Abstract}

Study objective: To assess the efficacy of intraoperative different inspired oxygen fractions $\left(\mathrm{FIO}_{2}\right)$ of 0.8 and 0.5 when compared with standard $\mathrm{FIO}_{2} 0.3$ in prevention of postoperative nausea and vomiting (PONV).

Design: A prospective, controlled, randomized, double-blind study.

Setting: General hospital, postanesthesia care unit (PACU) and gynecologic floor room. Patients: 120 ASA physical status I and II women, aged 21 to $76 \mathrm{y}$, undergoing elective gynecologic laparoscopic surgery.

Interventions: Patients were randomized to receive gas mixture of $30 \%$ oxygen in air (FI $\mathrm{O}_{2}=0.3$, group $\left.\mathrm{G} 30\right), 50 \%$ oxygen in $\operatorname{air}\left(\mathrm{FIO}_{2}=0.5\right.$, group $\left.\mathrm{G} 50\right)$ or $80 \%$ oxygen in air $\left(\mathrm{FIO}_{2}=0.8\right.$, group $\left.\mathrm{G} 80\right), \mathrm{n}=36$ in each group. A standardized sevoflurane general anesthesia, postoperative pain management and antiemetic regimen were used.

Measurements: The incidence of nausea, vomiting or both was assessed for early $(0-2 \mathrm{~h})$ and late PONV (2-24h) along with the use of rescue antiemetic, degree of nausea and severity of pain.

Main results: There was no overall difference in the incidence of PONV at early and late assessment periods among the three groups. Patients in G80 had significantly less vomiting than G30 at 2 hours, $3 \%(1 / 36)$ vs. $22 \%$ (8/36), respectively, $\mathrm{P}=0.028$. Nausea scores, rescue antiemetic use, pain scores and opioid consumption were not different among the groups. Conclusion: High intraoperative $\mathrm{FIO}_{2}$ of 0.8 and $\mathrm{FIO}_{2}$ of 0.5 does not prevent PONV in patients without antiemetic prophylaxis. Intraoperative $\mathrm{FIO}_{2}$ of 0.8 has beneficial effect on early vomiting only.

\section{Introduction}


Gynecologic laparoscopic surgery increases the risk for postoperative nausea and vomiting (PONV) with an incidence as high as $80 \%$ [1]. Pharmacological prophylaxis does not eliminate the incidence of PONV completely and can increase the costs and the risk of adverse events [2]. Supplemental oxygen may be an additional simple method in multimodal PONV prophylaxis. The published data to date remain controversial. Intraoperative $\mathrm{FIO}_{2}$ of 0.8 was reported as effective as ondansetron prophylaxis in women undergoing general anesthesia for prolonged gynecologic laparoscopic surgery [3]. On the contrary, two reports suggested that perioperative $\mathrm{FIO}_{2}$ of 0.8 did not prevent PONV after general anesthesia for short ambulatory gynecologic laparoscopic procedures [4,5] (Table 1). A factorial trial of six interventions for the prevention of postoperative nausea and vomiting which included mixed general and gynecological surgery found no differences in the incidence of PONV in patients receiving $\mathrm{FIO}_{2}$ of 0.8 when compared with $\mathrm{FIO}_{2}$ of 0.3 but the effect of oxygen on early PONV was not analyzed [6]. Recent meta-analysis concluded that $\mathrm{FIO}_{2}$ of 0.8 compared with $\mathrm{FIO}_{2}$ of 0.3-0.4 did not reduce PONV after general anesthesia for abdominal and nonabdominal surgery although the early vomiting was significantly reduced in abdominal surgery patients [7]. Nevertheless, studies with patients receiving $\mathrm{FIO}_{2}$ of 0.5 were excluded from the meta-analysis. $\mathrm{FIO}_{2}$ of 0.5 is more commonly used in anesthesia practice when higher $\mathrm{FIO}_{2}$ is desirable. One study found no effect of $\mathrm{FIO}_{2}$ of 0.5 on PONV in patients undergoing breast surgery but suggested beneficial effect on early postoperative vomiting [8]. Recent PONV consensus panel concluded that supplemental oxygen had no beneficial effects on PONV. However, this conclusion was based on $\mathrm{FIO}_{2}$ of 0.8 [9]. There is paucity of data on the influence of $\mathrm{FIO}_{2}$ of 0.5 on PONV and the effects of oxygen on early and late PONV. We therefore designed a prospective, randomized, controlled, double blind study to test the hypothesis that high intraoperative oxygen $\left(\mathrm{FIO}_{2}\right.$ of 0.5 and $\mathrm{FIO}_{2}$ of 0.8$)$ compared with 
routine $\mathrm{FIO}_{2} 0.3$ reduces the incidence of nausea and vomiting over the initial 24

postoperative hours in women underwent elective gynecological laparoscopic surgery during general anesthesia. The potential for the dose/response effects in reducing the incidence of PONV with higher $\mathrm{FIO}_{2}$ was evaluated as well. 


\section{Methods}

After the local ethics committee approval, written informed consent was obtained from 120 adult patients classified as ASA (American Society of Anesthesiologists) physical status I and II, presenting for elective laparoscopic gynecological surgery at General Hospital Zadar, Croatia. The exclusion criteria were as follows: obesity (BMI $>30 \mathrm{~kg} / \mathrm{m}^{2}$ ), pulmonary diseases, pregnancy or breast feeding, known hypersensitivity to drugs used in the study protocol, use of antiemetics, psychotropic drugs, hormones and steroids within three days before surgery. Patients with comorbidities that may have an influence on PONV were also excluded, i.e. diseases which impaired gastric motility (diabetes mellitus, chronic cholecystitis, gastric and intestinal disease, neuromuscular disorders, neuropathies and liver dysfunction), vestibular disease, history of migraine headache, central nervous system injury, renal impairment, irregular menstrual cycles (duration of $<21$ or $>35$ days and/or variations between cycles $>4$ days), alcoholism and opioid addiction. After study enrollment, patients were excluded if they unexpectedly developed intraoperative drug allergy, severe intraoperative hypotension, perioperative hypoxia, excessive blood loss, difficult intubation, in open procedures or postoperative complications.

All patients received $7.5 \mathrm{mg}$ of midazolam PO 1 hour before the surgery with no prophylactic antiemetics. Standard monitoring was used including electrocardiography, noninvasive blood pressure, pulse oximetry and capnography. Anesthesia was induced with thiopental $5 \mathrm{mg} / \mathrm{kg}$, fentanyl 1-2 $\mu \mathrm{g} / \mathrm{kg}$, and vecuronium $0.1 \mathrm{mg} / \mathrm{kg}$ IV. Patients' lungs were manually ventilated via face mask with oxygen $\mathrm{FIO}_{2}=1.0$ for 3 minutes before endotracheal intubation. Patients were randomized by computer-generated random numbers to receive a gas mixture consisting of $30 \%$ oxygen in air $\left(\mathrm{FIO}_{2}=0.3\right.$, group $\left.\mathrm{G} 30\right), 50 \%$ oxygen in $\operatorname{air}\left(\mathrm{FIO}_{2}=0.5\right.$, group $\left.\mathrm{G} 50\right)$ or $80 \%$ oxygen in air $\left(\mathrm{FIO}_{2}=0.8\right.$, group $\left.\mathrm{G} 80\right)$. Anesthesia was maintained with sevoflurane (end tidal concentration $\sim 1$ minimum alveolar concentration [MAC], $1.5-2 \mathrm{vol} \%$ ) and 
supplemental bolus doses of fentanyl IV $(1 \mu \mathrm{g} / \mathrm{kg})$ to keep heart rate and blood pressure within $20 \%$ of baseline values and additional vecuronium was administered to maintain one or two twitches on the train-of-four monitor. All patients received $10 \mathrm{ml} / \mathrm{kg} / \mathrm{h}$ of crystalloids during surgery. Insertion of a nasogastric tube was not used. Patients' lungs were mechanically ventilated to keep normocapnia (end tidal $\mathrm{CO}_{2} 32-38 \mathrm{mmHg}$ ). All laparoscopies were performed with $\mathrm{CO}_{2}$ insufflation and the patients were placed in a Trendelenburg position. Sevoflurane was discontinued at the start of skin closure. At the end of surgery neuromuscular blockade was antagonized with neostigmine $2.5 \mathrm{mg}$ and atropine $1 \mathrm{mg}$ IV. Postoperatively, patients received $5 \mathrm{ml} / \mathrm{kg} / \mathrm{h}$ of crystalloids and were allowed to drink after the first 3 hours, if tolerated. After the surgery all patients breathed room air during the 24 hours follow-up period. The incidence of postoperative nausea (PON), vomiting (POV) and the use of rescue antiemetic were collected at 2 and 24 hours after surgery. Severity of postoperative nausea and pain were evaluated using a $100 \mathrm{~mm}$ visual analog scale (VAS) at the same time points (VAS $0=$ no pain/nausea, $100=$ maximal pain/nausea). A nausea VAS score was measured for each episode, but the highest score during the early $(0-2 \mathrm{~h})$ and the late $(2-24 \mathrm{~h})$ period was used for statistical analysis.

Patients were considered to have had PONV if they experienced at least one episode of nausea, vomiting or retching or any combination of these during initial 24 postoperative hours. Postoperative vomiting was defined as at least one episode of vomiting or retching that occurred within 24 postoperative hours. PONV was defined as early (within first 2 hours in postoperative recovery area) or late (2-24 postoperative hours, on the ward). Three clinical nurses, specifically trained for the study, blinded to the randomization and the anesthesia technique used, collected the data. Metoclopramide $0.2 \mathrm{mg} / \mathrm{kg}$ IV was used as the rescue antiemetic and repeated if necessary. The administration of rescue antiemetic was based on the following criteria: patients who had two or more episodes of vomiting or retching within a period of $30 \mathrm{~min}$, any nausea lasting more than $15 \mathrm{~min}$ or nausea VAS score $50 \mathrm{~mm}$ or 
greater, or when a patient requested treatment. Pain VAS score and total amount of postoperative opioids were recorded at $2 \mathrm{~h}$ and 24 hours after surgery. Diclofenac $75 \mathrm{mg}$ IM was given immediately after surgery and if needed 12 hours later. For severe pain (VAS >40 $\mathrm{mm}$ ) meperidine $25 \mathrm{mg}$ up to $100 \mathrm{mg}$ IV was used. All patients stayed in the hospital for at least 24 hours.

Sample size calculations as well as power analysis were analyzed by nQuery Advisor 7.0 (Statistical Solutions, Saugus, MA, USA). Sample size calculation was based on expected incidence of PONV 44\% in group G30 and 50\% reduction of PONV based on the data from a published study in gynecologic laparoscopic surgery [3]. Power analysis showed that 37 patients per group would provide $80 \%$ power for detecting $50 \%$ reduction in the incidence of PONV with each treatment at a 2 -sided $\alpha$ level of 0.05 . Forty patients were randomized to each group to allow 5 to $10 \%$ drop out rate. The data were analyzed using GraphPad Prism 5, v. 5.01 GraphPad Software Inc, San Diego, CA, USA. Quantitative values like demographic data, number of vomiting episodes per patient, VAS data and PONV risk scores were compared among three groups using ANOVA or Kruskal-Wallis test. Demographic categorical data, the incidence of nausea and vomiting as well as incidence of nausea and vomiting separately and metoclopramide administration were analyzed by Pearson ChiSquare and Fisher's exact test where appropriate. Risk scores for PONV were calculated according to Apfel et al. [10]. Linear trend in reducing the incidence of POV with higher $\mathrm{FIO}_{2}$ was tested by the Chi squared test for linear trend. Data were expressed as mean values (SD), median and range (minimal and maximal value) or number, percentage and $95 \%$ confidence interval $(\mathrm{CI})$. P value of $<0.05$ was considered statistically significant. 


\section{Results}

One hundred and eight of 120 patients, between 21 and 76 years old, completed the study $(\mathrm{G} 30=36, \mathrm{G} 50=36, \mathrm{G} 80=36)$. A total of 12 patients were excluded from the analysis (Figure 1). Patients' demographic, intraoperative data and PONV risk scores were not different among the three groups (Table 2). The incidence of early vomiting was significantly decreased with increasing $\mathrm{FIO}_{2}$ (Table 3). $\mathrm{FIO}_{2}$ of 0.8 significantly decreased the incidence of early postoperative vomiting compared with $\mathrm{FIO}_{2}$ of $0.3,3 \%,(1 / 36 ; 95 \% \mathrm{CI} 0.07-14)$ and $22 \%,(8 / 36 ; 95 \%$ CI 10-39), respectively $(\mathrm{P}=0.028)$. There was no difference in early POV in G50, 11\%, (4/36; 95\% CI 3-26) vs. G30, 22\%, (8/36; 95\% CI 10-39) (P=0.343) nor G80, 3\%, (1/36; 95\% CI 0.07-14) vs. G50, 11\%, (4/36; 95\% CI 3-26) (P=0.357) (Table 3). The incidence of vomiting was reduced in groups with supplemental oxygen, G50 and G80, but there was no overall difference among the three groups at 24 hours (Table 3). Patients with higher oxygen inspiratory fraction had fewer number of vomiting episodes (Table 3). There was no difference in severe vomiting $\mathrm{G} 30=5$ patients $(14 \%)$, G50 $=0$ and $\mathrm{G} 80=3(8 \%)$, $\mathrm{P}=0.077$. The incidence of nausea was not significantly different among groups, neither for early nor late postoperative period. VAS scores for nausea were not significantly different among groups. There was no difference in the incidence of severe nausea G30=8 (22\%), $\mathrm{G} 50=5(14 \%)$ and $\mathrm{G} 80=6(17 \%), \mathrm{P}=0.639$.

Patients received same amount of the rescue antiemetic metoclopramide $\mathrm{G} 30=8$ patients $(22 \%), \mathrm{G} 50=5(14 \%)$ and $\mathrm{G} 80=5(14 \%), \mathrm{P}=0.549$. The VAS pain scores at $2 \mathrm{~h}$ and 24 hours after surgery were similar among groups (Table 4). Amount of intraoperative opioids and postoperative pain medications were similar among the three groups (Table 4). There were no other adverse events reported. 


\section{Discussion}

Our study suggests that higher intraoperative inspired oxygen fractions $\mathrm{FIO}_{2} 0.8$ and $\mathrm{FIO}_{2} 0.5$ in comparison with routine $\mathrm{FIO}_{2} 0.3$ have no effect on PONV in first 24 hours after gynecologic laparoscopic surgery. $\mathrm{FIO}_{2}$ of 0.8 as compared with $\mathrm{FIO}_{2}$ of 0.3 decreases the incidence of early postoperative vomiting, from $22 \%$ to $3 \%$. The number of vomiting episodes was also decreased.

The influence of supplemental perioperative $\mathrm{O}_{2}$ in laparoscopic gynecological surgery was rarely investigated only in 2 published studies with opposite results [3,5]. Goll et al. [3] found that $\mathrm{FIO}_{2}$ of 0.8 when administered during gynecologic laparoscopic surgery halved the incidence of PONV for 24 postoperative hours from $44 \%$ to $22 \%$ compared with $\mathrm{FIO}_{2}$ of 0.3 . On the contrary, Purhonen et al. [5] found that perioperative $\mathrm{FIO}_{2}$ of 0.8 did not reduce the incidence of PONV after ambulatory gynecological laparoscopy, which is in agreement with our findings. That study [5] did not find any difference in early vomiting although the number of patients who vomited in PACU was higher in $\mathrm{FIO}_{2}$ of 0.3 than in $\mathrm{FIO}_{2}$ of 0.8 group. The incidence of early vomiting in our study was significantly higher in patients with $\mathrm{FIO}_{2}$ of 0.3 compared to Purhonen study, $22 \%$ vs. $8 \%$, respectively.

Purhonen's group [8] investigated influence of $\mathrm{FIO}_{2}$ of 0.5 in breast surgery and did not find the difference in PONV compared with $\mathrm{FIO}_{2}$ of $0.3,89 \%$ vs. $82 \%$, at 24 hours, but the incidence of POV at 2 hours was significantly different, $0 \%$ vs. $12 \%$, respectively. In the current study only $\mathrm{FIO}_{2}$ of 0.8 decreased the incidence of early POV compared with $\mathrm{FIO}_{2}$ of 0.3 (Table 3). The incidence of early vomiting was decreased as $\mathrm{FIO}_{2}$ increased. Only one study attempted to correlate the influence of three different intraoperative $\mathrm{FIO}_{2}(0.3,0.5$ and 0.8) on PONV after general anesthesia in breast surgery patients [11]. This study found no difference in the incidence of PONV 24 hours postoperatively, $35 \%$ vs. $45 \%$ vs. $30 \%$, respectively [11]. However, the decreased incidence of early PONV (30\% vs. 20\% vs. 10\%) 
with increasing $\mathrm{FIO}_{2}\left(\mathrm{FIO}_{2} 0.3, \mathrm{FIO}_{2} 0.5\right.$ and $\mathrm{FIO}_{2} 0.8$, respectively) showed similar results. There appears to be a dose response relationship for early POV. This is suggested by statistically significant linear trend $(\mathrm{P}=0.01)$, as tested by the Chi squared test for linear trend, in reducing the incidence of POV with higher $\mathrm{FIO}_{2}$ (Table 3). A larger prospective study would be needed to confirm this relationship.

Recent meta-analysis [7] showed that $\mathrm{FIO}_{2}$ of 0.8 compared with $\mathrm{FIO}_{2}$ 0.3-0.4 does not decrease incidence of PONV in abdominal and non-abdominal surgery at 24 hours. Early POV was not found to be decreased in non-abdominal surgery, but was decreased in abdominal surgery in the high $\mathrm{FIO}_{2}$ group. This suggests that the mechanism might be intestinal ischemia and release of short acting metabolites which triggers POV. Although serotonin was suggested as a trigger for POV after abdominal surgery, its role in POV was disputed, since serotonin plasma half life is only few minutes and peaks intraoperatively with no active metabolites postoperatively $[7,12]$.

$\mathrm{FIO}_{2}$ of 0.5 was evaluated because it is commonly used in anesthesia practice when higher supplemental oxygen is desired. Use of $\mathrm{FIO}_{2}$ higher than 0.5 is not without risks [13-17]. There were no side effects related to high $\mathrm{FIO}_{2}$ administration.

There are several limitations to this study. The results may not be generalized to other populations as the results were obtained for only one type of surgery and from a single hospital. The power analysis was calculated according to results of published data but the base incidence was less (44\% vs. 36\%, respectively) [3]. Therefore, the study may have not enough power to show statistical difference among all groups to avoid type I statistical error. Assuming the same trend in the incidence of early POV were to persist, a study with sample size of 175 patients in each group would have been necessary to produce a statistically significant difference among each of three groups with a power of 0.8 and $\alpha<0.05$. Expected intervention effect of 50\% PONV reduction based on two previously published studies in 
gynecological laparoscopy might to be too optimistic when compared with single antiemetic risk reduction by $26 \%$ in a factorial trial of six interventions for the prevention of PONV $[3,5,6]$.

In conclusion, higher intraoperative oxygenation did not reduce the PONV during first 24 hours, however it decreased the incidence of early postoperative vomiting. Therefore, in patients undergoing surgical procedures associated with higher risk of PONV, such as laparoscopic gynecologic surgery, the use of high inspired oxygen concentrations has limited role in preventing the occurrence of this adverse event, and cannot be recommended as a part of routine anti-PONV strategy. 


\section{References}

[1] Eriksson H, Korttila K. Recovery profile after desflurane with or without ondansetron compared with propofol in patients undergoing outpatient gynecological laparoscopy. Anesth Analg 1996; 82: 533-8.

[2] Sprung J, Choudhry FM, Hall BA. Extrapyramidal reactions to ondansetron: Crossreactivity between ondansetron and prochlorperazine? Anesth Analg 2003; 96: 1374-6. [3] Goll V, Akça O, Greif R et al. Ondansetron is no more effective than supplemental intraoperative oxygen for prevention of postoperative nausea and vomiting. Anesth Analg 2001; 92: 112-7.

[4] McKeen DM, Arellano R, O'Connell C. Supplemental Intraoperative Oxygen and 24 Hour Postoperative Nausea/Vomiting in Ambulatory Surgery. Anesthesiology 2007; 107: A1019.

[5] Purhonen S, Turunen M, Ruohoaho U-M, Niskanen M, Hynynen M. Supplemental oxygen does not reduce the incidence of postoperative nausea and vomiting after ambulatory gynecologic laparoscopy. Anesth Analg 2003; 96: 91-6.

[6] Apfel CC, Korttila K, Abdalla M et al. A factorial trial of six interventions for the prevention of postoperative nausea and vomiting. N Engl J Med 2004; 350: 2441-51. [7] Orhan-Sungur M, Kranke P, Sessler D, Apfel CC. Does supplemental oxygen reduce postoperative nausea and vomiting? A meta-analysis of randomized controlled trials. Anesth Analg 2008; 106: 1733-8.

[8] Purhonen S, Niskanen M, Wüstefeld M, Mustonen P, Hynynen M. Supplemental oxygen for prevention of nausea and vomiting after breast surgery. Br J Anaesth 2003; 91: 284-7. 
[9] Gan TJ, Meyer TA, Apfel CC et al. Society of ambulatory anesthesia guidelines for the management of postoperative nausea and vomiting. Anesth Analg 2007; 105: 1615-28.

[10] Apfel CC, Läärä E, Koivuranta M, Greim C-A, Roewer N. A simplified risk score for predicting postoperative nausea and vomiting. Conclusions from cross-validations between two centers. Anesthesiology 1999; 91: 693-700.

[11] Bhatnagar S, Mishra S, Gupta M, Singhal AK, Mandal AS. Effects of different concentrations of intraoperative supplemental oxygen on post-operative nausea and vomiting (PONV) in patients under going modified radical mastectomy. Internet $\mathbf{J}$ Anesthesiol 2005; 9.

[12] Nicole PC, Trépanier CA, Lessard MR. Nausea and vomiting after laparoscopic surgery are not associated with an increased paripheral release of serotonin. Can J Anesth 2002; 49: 453-7.

[13] Reber A, Engberg G, Wegenius G, Hedenstierna G. Lung aeration. The effect of preoxygenation and hyperoxygenation during total intravenous anaesthesia. Anaesthesia 1996; 51: 733-7.

[14] Katz JA, Campbell L. Fire during thoracotomy: a need to control the inspired oxygen concentration. Anesth Analg 2005; 101: 612.

[15] Singla AK, Campagna JA, Wright CD, Sandberg WS. Surgical field fire during a repair of bronchoesophageal fistula. Anesth Analg 2005; 100: 1062-4.

[16] Akça O, Podolsky A, Eisenhuber E et al. Comparable postoperative pulmonary atelectasis in patients given $30 \%$ or $80 \%$ oxygen during and 2 hours after colon resection. Anesthesiology 1999; 91: 991-8.

[17] Kabon B, Kurz A. Optimal perioperative oxygen administration. Curr Opin Anaesthesiol 2006; 19: 11-8. 
FIGURE 1 Flow diagram of patients' distribution.

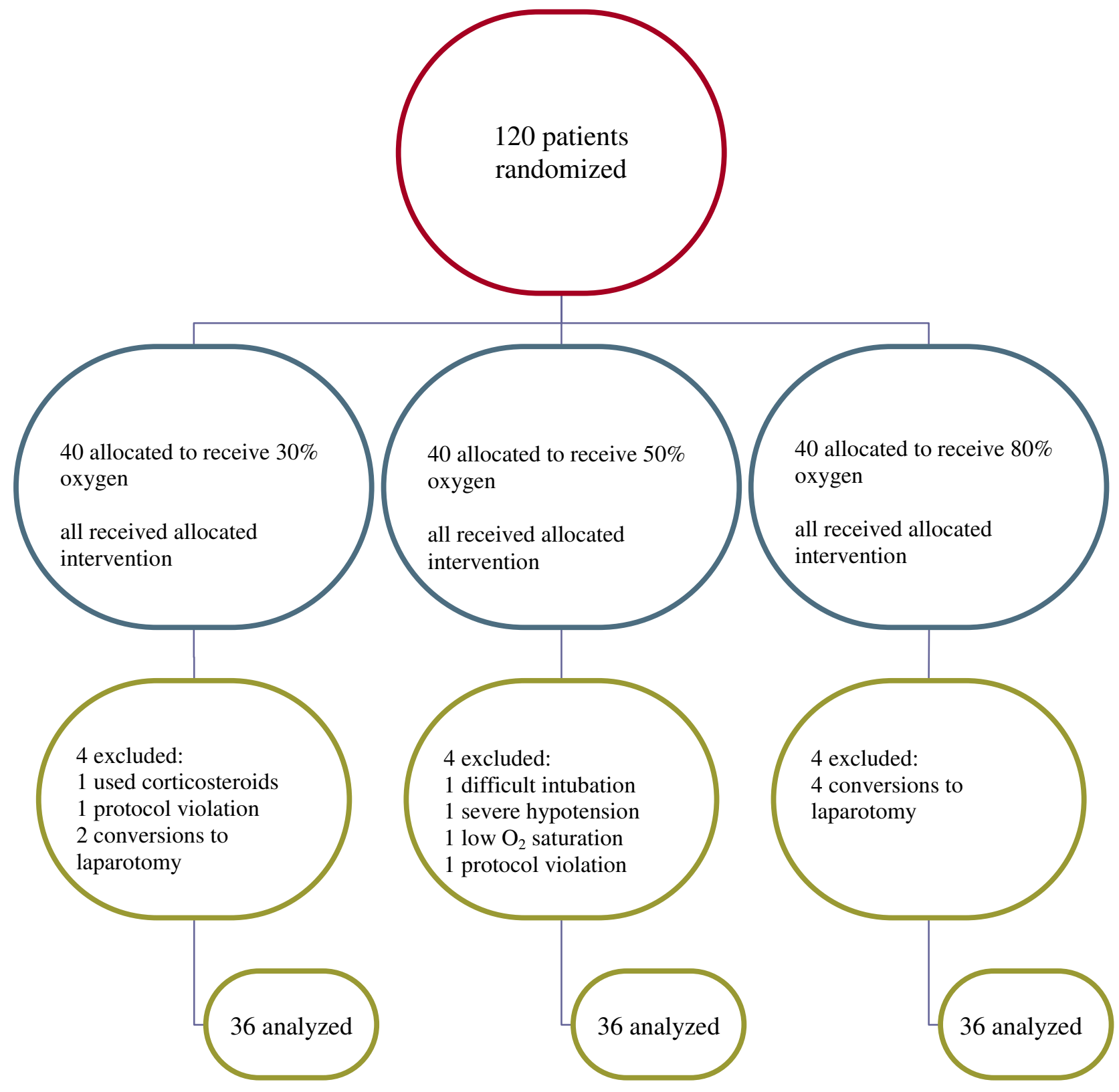


TABLE 1 Studies about the influence of high inspired oxygen fractions $\left(\mathrm{FIO}_{2}\right)$ on the incidence of PONV cited.

\begin{tabular}{|c|c|c|c|c|c|}
\hline $\begin{array}{l}\text { Reference } \\
\text { [Number] }\end{array}$ & $\begin{array}{l}\text { Oxygen concentration } \\
\text { (n) }\end{array}$ & $\begin{array}{l}\text { Type of } \\
\text { anesthesia/ } \\
\text { surgery }\end{array}$ & $\begin{array}{l}\text { Supplemental } \\
\text { oxygen } \\
\text { administration } \\
\end{array}$ & Outcomes & $\begin{array}{l}\text { Incidence of PONV } \\
\text { significance }\end{array}$ \\
\hline $\begin{array}{l}\text { Goll et al., } \\
2001 . \\
{[3]}\end{array}$ & $\begin{array}{l}30 \%(80) \text { vs. } 80 \%(79) \\
\text { vs. } 30 \%+\text { ondansetron } \\
(81)\end{array}$ & $\begin{array}{l}\text { general/ } \\
\text { gynecologic } \\
\text { laparoscopic } \\
\text { surgery }>1 \mathrm{~h}\end{array}$ & $\begin{array}{l}\text { intraoperative+ } \\
2 \mathrm{~h} \text { postop. } 2 \mathrm{~L} / \mathrm{minO}_{2}\end{array}$ & $\begin{array}{l}\text { PON, POV, PONV } \\
(0-6 h, 6-24 h, 0-24 h)\end{array}$ & $\begin{array}{l}\text { PONV at } 24 \mathrm{~h}(44 \% \text { vs. } \\
\text { Significant reduction wi }\end{array}$ \\
\hline $\begin{array}{l}\text { McKeen et al. } \\
\text { (abstract) } \\
2007 . \\
{[4]}\end{array}$ & $\begin{array}{l}30 \%(145) \text { vs. } 80 \% \\
(147)\end{array}$ & $\begin{array}{l}\text { general/ } \\
\text { ambulatory } \\
\text { laparoscopic } \\
\text { tubal ligation }\end{array}$ & intraoperative & $\begin{array}{l}\text { PON, POV, PONV } \\
\text { (PACU stay, post- } \\
\text { discharge, } 0-24 \mathrm{~h} \text { ) }\end{array}$ & PONV 24h (65.3\% vs. \\
\hline $\begin{array}{l}\text { Purhonen et al. } \\
2003 . \\
{[5]}\end{array}$ & $30 \%$ (50) vs. $80 \%$ (49) & $\begin{array}{l}\text { general/ } \\
\text { ambulatory } \\
\text { gynecological } \\
\text { laparoscopy } \\
\end{array}$ & $\begin{array}{l}\text { intraoperative }+ \\
\text { 1h postop. }\end{array}$ & $\begin{array}{l}\text { PONV,PON, POV } \\
\text { (PACU, step-down unit } \\
=\text { Phase II, } \\
0-24 \mathrm{~h} \text { ) }\end{array}$ & PONV at $24 \mathrm{~h}(62 \%$ vs.5 \\
\hline $\begin{array}{l}\text { Apfel et al. } \\
2004 . \\
{[6]}\end{array}$ & $\begin{array}{l}80 \% \text { (280) vs. } 30 \% \\
(279)\end{array}$ & $\begin{array}{l}\text { general/gynec } \\
\text { ologic }+ \\
\text { mixed surgery }\end{array}$ & perioperative & PONV $(0-24 h)$ & PONV at $24 \mathrm{~h}(31 \%$ vs. \\
\hline $\begin{array}{l}\text { Orhan-Sungur } \\
\text { et al. } 2008 . \\
\text { [7] }\end{array}$ & $\begin{array}{l}\text { meta-analysis } 10 \\
\text { studies } 30 \%-40 \% \\
(869) \text { vs. } 80 \%(860)\end{array}$ & $\begin{array}{l}\text { general/gynec } \\
\text { ologic }+ \\
\text { mixed surgery }\end{array}$ & $\begin{array}{l}\text { intraoperative, } \\
\text { perioperative }\end{array}$ & $\begin{array}{l}\text { PONV(0-6h, 6-24h, } \\
0-24 h)\end{array}$ & $\begin{array}{l}\text { PONV at } 24 \mathrm{~h}(33 \% \text { vs. } \\
\text { Significant reduction PC } \\
\text { RR } 0.42[95 \% \mathrm{CI}]=0.22\end{array}$ \\
\hline $\begin{array}{l}\text { Purhonen et al. } \\
2003 . \\
{[8]}\end{array}$ & $30 \%$ (49) vs. $50 \%$ (47) & $\begin{array}{l}\text { general/breast } \\
\text { surgery }\end{array}$ & intraop. $+2 \mathrm{~h}$ postop. & $\begin{array}{l}\text { PONV,PON, POV (0-2h, } \\
2-6 h, 6-24 h, 0-24 h)\end{array}$ & $\begin{array}{l}\text { PONV at } 24 \mathrm{~h}(82 \% \text { vs. } \\
\text { Significant reduction } \mathrm{PC} \\
\mathrm{O}_{2}, \mathrm{P}<0.05\end{array}$ \\
\hline $\begin{array}{l}\text { Bhatnagar et } \\
\text { al. } 2005 . \\
{[11]}\end{array}$ & $\begin{array}{l}30 \%(20) \text { vs. } 50 \%(20) \\
\text { vs. } 80 \%(20)\end{array}$ & $\begin{array}{l}\text { general/ } \\
\text { radical } \\
\text { mastectomy }\end{array}$ & $\begin{array}{l}\text { intraop.+ postop.(if } \\
\mathrm{O}_{2} \text { saturation }<95 \% \text { ) }\end{array}$ & $\begin{array}{l}\text { PONV (0-2h, 2-6h, 6-24h, } \\
0-24 h), \text { PON }(0-24 h)\end{array}$ & $\begin{array}{l}\text { PONV at } 24 \mathrm{~h}(35 \% \text { vs. } \\
\text { PONV at } 2 \mathrm{~h}(30 \% \text { vs. } 2\end{array}$ \\
\hline
\end{tabular}

$\mathrm{RR}=$ Relative Risk, $\mathrm{OR}=$ Odds Ratio, $\mathrm{CI}=$ Confidence Interval, $\mathrm{n}=$ study subjects 
TABLE 2 Patients' demographics.

\begin{tabular}{|c|c|c|c|}
\hline & G30 $(n=36)$ & G50 $(n=36)$ & G80 $(n=36)$ \\
\hline Age (yr) & $35.0 \pm 9.9$ & $37.2 \pm 7.9$ & $41.4 \pm 15.1$ \\
\hline $\mathrm{BMI}\left(\mathrm{kg} / \mathrm{m}^{2}\right)$ & $22.5 \pm 3.2$ & $23.0 \pm 3.6$ & $22.8 \pm 2.7$ \\
\hline ASA physical status (I/II) & $29 / 7$ & $29 / 7$ & $23 / 13$ \\
\hline Smoking $\mathrm{n}(\%)$ & $16(44 \%)$ & $18(50 \%)$ & $16(44 \%)$ \\
\hline \multicolumn{4}{|l|}{ History of motion sickness } \\
\hline and/or PONV n (\%) & $11(31 \%)$ & $15(42 \%)$ & $13(36 \%)$ \\
\hline Duration of anesthesia (min) & $74.2 \pm 38.7$ & $74.4 \pm 34.5$ & $60.5 \pm 25.1$ \\
\hline Duration of surgery (min) & $56.4 \pm 36.5$ & $57.0 \pm 33.6$ & $44.0 \pm 23.4$ \\
\hline \multicolumn{4}{|l|}{ Type of surgery (n) } \\
\hline \multicolumn{4}{|l|}{ Ovarian cystectomy / } \\
\hline Tumor resection & 22 & 19 & 22 \\
\hline Myomectomy & 5 & 12 & 5 \\
\hline \multicolumn{4}{|l|}{ Laparoscopic assisted } \\
\hline vaginal hysterectomy & 3 & 0 & 0 \\
\hline Laparoscopy for infertility & 6 & 5 & 9 \\
\hline \multicolumn{4}{|l|}{ Risk score for PONV* $\mathrm{n}(\%)$} \\
\hline 1 & $10(28 \%)$ & $7(19 \%)$ & $11(31 \%)$ \\
\hline 2 & $15(42 \%)$ & $15(42 \%)$ & $11(31 \%)$ \\
\hline 3 & $11(31 \%)$ & $11(31 \%)$ & $12(33 \%)$ \\
\hline 4 & $0(0 \%)$ & $3(8 \%)$ & $2(6 \%)$ \\
\hline $\begin{array}{l}\text { Average number of risk } \\
\text { scores }\end{array}$ & $2.03 \pm 0.77$ & $2.14 \pm 0.93$ & $2.28 \pm 0.88$ \\
\hline
\end{tabular}

No statistical differences among groups $\left(\mathrm{G} 30=\mathrm{FIO}_{2}\right.$ 0.3, G50=FIO $\left.{ }_{2} 0.5, \mathrm{G} 80=\mathrm{FIO}_{2} 0.8\right)$. Data presented as mean \pm SD or $n(\%)$.

* Simplified risk score for PONV by Apfel et al.: female gender, history of motion sickness or PONV, non-smoking, the use of postoperative opioids. None, one, two, three or four risk factors indicate $10 \%, 21 \%, 39 \%, 61 \%$ or $79 \%$ incidence of PONV. 
TABLE 3 Postoperative nausea and vomiting after laparoscopic gynecological surgery.

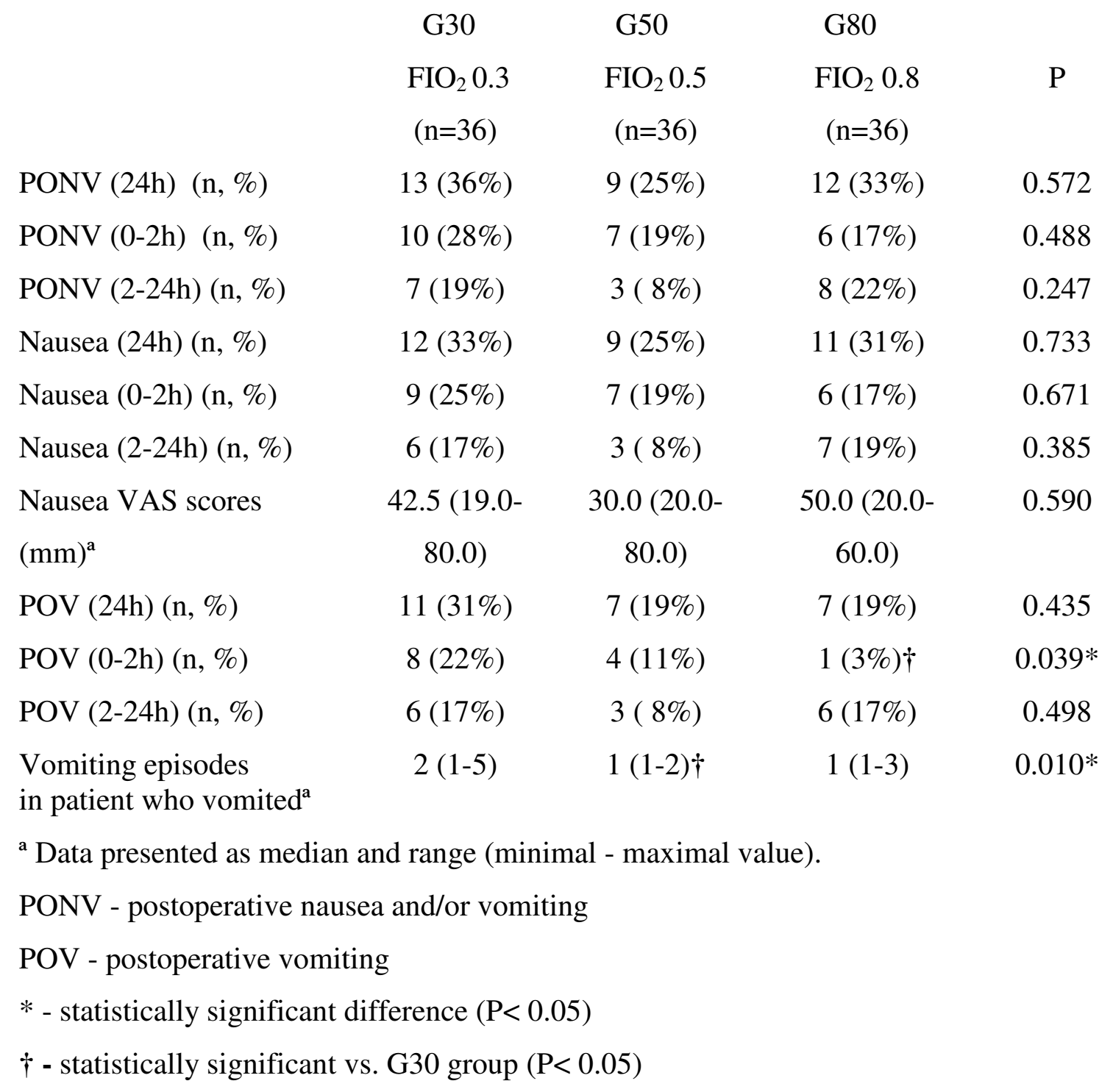


TABLE 4 Pain visual analog scale (VAS) score and the amount of opioid use.

\begin{tabular}{|l|l|l|l|c|}
\hline & G30 $(\mathrm{n}=36)$ & G50 $(\mathrm{n}=36)$ & G80 $(\mathrm{n}=36)$ & P \\
\hline $\begin{array}{l}\text { Pain VAS scores }(\mathrm{mm}) \\
\text { Postop at 2 h }\end{array}$ & $\begin{array}{l}20.0(0-58.0) \\
24 \mathrm{~h}\end{array}$ & $\begin{array}{l}20.0(10.0-50.0) \\
10.0(0-30.0)\end{array}$ & $\begin{array}{l}20.0(10.0-50.0) \\
10.0(0-40.0)\end{array}$ & $\begin{array}{l}0.646 \\
0.151\end{array}$ \\
\hline $\begin{array}{l}\text { Intraoperative fentanyl } \\
(\mu \mathrm{g})\end{array}$ & $188(75-450)$ & $200(100-300)$ & $200(100-300)$ & 0.06 \\
\hline $\begin{array}{l}\text { Postoperative } \\
\text { meperidine }(\mathrm{mg})\end{array}$ & $0(0-100)$ & $0(0-50)$ & $0(0-65)$ & 0.276 \\
\hline
\end{tabular}

All data are median and range (minimal - maximal value). 